\title{
Influence of Valence Band Modifications on Hydrogen Absorption in Zr-Pd Alloy Thin Films
}

\author{
B. Jabloński ${ }^{a, b, *}$, S. PACANOWski ${ }^{a}$, M. Werwiński $^{a}$, A. MARCZYŃSKA $^{a}$, \\ H. DAWCZAK-DĘBICKI ${ }^{a, c}$, A. SZAJEK ${ }^{a}$, AND L. SMARDZ ${ }^{a}$ \\ ${ }^{a}$ Institute of Molecular Physics, Polish Academy of Sciences, M. Smoluchowskiego 17, 60-179 Poznań, Poland \\ ${ }^{b}$ Faculty of Technical Physics, Poznań University of Technology, Piotrowo 3, 60-965 Poznań, Poland \\ ${ }^{c}$ Faculty of Physics, Adam Mickiewicz University, Umultowska 85, 61-614 Poznań, Poland
}

\begin{abstract}
We study the valence band modifications of in-situ prepared nano- and polycrystalline Pd-Zr alloy thin films using X-ray photoelectron spectroscopy. Results were compared with valence bands calculated by ab initio methods. Furthermore, hydrogen absorption and desorption kinetics under pressure of about 570 mbar were studied in $\mathrm{Pd}$ covered nanocrystalline $\mathrm{ZrPd}_{2}$ alloy thin film. Results showed that modifications of the valence band of the nanocrystalline alloy thin film could significantly influence on hydrogen absorption and desorption process.
\end{abstract}

DOI: 10.12693/APhysPolA.133.620

PACS/topics: 73.22.-f, 82.80.Pv

\section{Introduction}

Intermetallic compounds based on hydrogen absorbing elements usually also form stable hydrides. This is, for instance, the case of $\mathrm{PdZr}_{2}$ alloy [1]. However, a similar compound, $\mathrm{ZrPd}_{2}$ does not absorb hydrogen although both compounds have the same crystal structure and satisfy the empirical geometrical criteria for hydride formation [1]. Results of ab initio calculations performed for $\mathrm{ZrPd}_{2}$ single crystal revealed an unanticipated purely electronic origin [1].

In thin film materials dislocations and vacancies are present in higher density than in bulk material [2]. Even when the grain size is maximized by epitaxial film growth, dislocations are generated during the growth process to adjust for the lattice mismatch between the film and the substrate [3]. The local hydrogen affinity is different for these defects and therefore the materials properties are expected to be influenced by all of the mentioned microstructural components. It was shown in Ref. [4] that the valence bands of bulk nanocrystalline and nanocomposite $\mathrm{LaNi}_{5}$-based materials were broadened compared to those measured for polycrystalline samples. Furthermore, practically all of the mechanically alloyed nanomaterials showed significantly greater discharge capacity [5].

Membrane separations have potential advantages over other approaches to hydrogen purification [6-8]. Permeability calculations were performed for the potential candidates. After systematically examining all Pd-based intermetallics, no material was found to have higher hydrogen permeability than pure Pd. Moreover, it has been found very recently from theoretical calculations that $\mathrm{ZrPd}_{2}$ membrane have also potentially interesting

\footnotetext{
* corresponding author; e-mail:

beniamin.jablonski@ifmpan.poznan.pl
}

permeability $[9,10]$. Therefore, modification of the electronic structure of $\mathrm{ZrPd}_{2}$ films by the tuning of their microstructure could potentially improve hydrogen permeability.
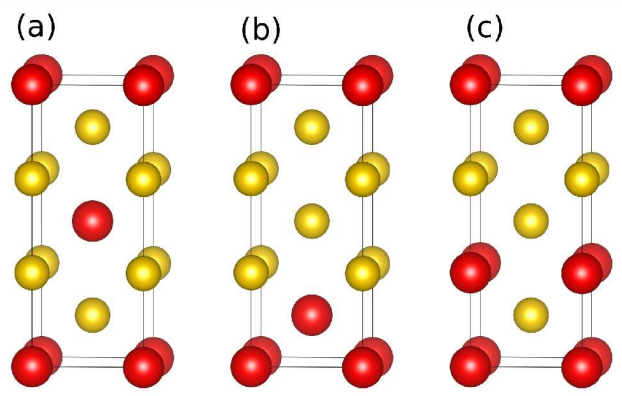

Fig. 1. The considered $\mathrm{ZrPd}_{2}$ models: (a) ordered, (b) $\mathrm{Zr}-\mathrm{Pd}$ antisites type I, (c) Zr-Pd antisites type II. The bigger red spheres represent $\mathrm{Zr}$, the smaller yellow ones stand for Pd.

In this paper, we study the electronic properties of polycrystalline and nanocrystalline $\mathrm{Zr}-\mathrm{Pd}$ alloy thin films using X-ray Photoelectron Spectroscopy (XPS) and $a b$ initio calculations.

\section{Experimental and theoretical methods}

The alloy thin films were prepared in the temperature range of $295 \mathrm{~K}-700 \mathrm{~K}$ using computer-controlled UHV magnetron co-sputtering [11, 12]. Pd and Zr targets were sputtered using DC and RF modes, respectively. The base pressure before the deposition process was lower than $5 \times 10^{-10}$ mbar. As a substrate we have used $\mathrm{Si}(100)$ wafers with an oxidised surface to prevent a silicide formation. Therefore we have applied a special heat treatment in UHV before deposition in order to obtain an epitaxial $\mathrm{SiO}_{2}$ surface layer [13, 14]. The chemical composition and the cleanness of all layers was 
checked in-situ, immediately after deposition, transferring the samples to an UHV $\left(4 \times 10^{-11}\right.$ mbar $)$ analysis chamber equipped with XPS. Details of the XPS measurements can be found in Ref. [15-17].

Furthermore, hydrogen absorption and desorption kinetics at room temperature (RT) and at a pressure of about 570 mbar were studied in $\mathrm{ZrPd}_{2}$ (covered by $10 \mathrm{~nm}-\mathrm{Pd}$ ) thin film using four-point resistivity measurements.

The theoretical photoemission spectra are based on the electronic structures calculated with the full-potential linearized augmented-plane wave (FP-LAPW) method implemented in the WIEN2k code [18]. The method of XPS spectra calculations is discussed in more details in our previous work [19]. In this work PerdewBurke-Ernzerhof form (PBE) [20] of the exchangecorrelation potential is selected. The effective on-site Coulomb interactions parameters $U(\mathrm{Zr})=2.4 \mathrm{eV}$ and $U(\mathrm{Pd})=3.7 \mathrm{eV}[21]$ have been taken into account in $\mathrm{GGA}(\mathrm{PBE})+U$ scheme. Plane wave cut-off parameter $R K_{\max }$ is set to 8 , which leads to above 500 basis functions. Relativistic effects are included with the second variational treatment of spin-orbit coupling. The total energy convergence criterion is set to $10^{-8} \mathrm{Ry} .32000 \mathrm{k}$ points is used in the whole Brillouin zone. Besides the ordered $\mathrm{ZrPd}_{2}$, two simplest models of the disordered structures were considered, see Fig. 1. In these models some $\mathrm{Zr}$ and $\mathrm{Pd}$ atoms have been exchanged on sites. All three structures have been fully relaxed, which means that the volume, c/a ratio and Wyckoff positions have been optimized. The resultant lattice parameters for ordered structure $(a=0.347 \mathrm{~nm}$ and $c=0.8755 \mathrm{~nm})$ are about $1.8 \%$ greater than the experimental ones [22], which means a decent agreement. The theoretical XPS for a single crystal with chemical disorder is evaluated as an average of three contributions: an ordered case and two cases with antisites, see Fig. 1.

\section{Results and discussion}

In Fig. 2 we show XPS core-level spectra of the freshly deposited nanocrystalline $\mathrm{ZrPd}_{2}$ alloy thin film and polycrystalline pure $\mathrm{Pd}$ and $\mathrm{Zr}$ thin films. The total thickness of the prepared thin films was about $100 \mathrm{~nm}$. Due to well known high reactivity of zirconium with oxygen we have prepared the nanocrystalline alloy thin film after an additional heating of the sample holder and substrate at $700 \mathrm{~K}$ for $3 \mathrm{~h}$ and cooling to $295 \mathrm{~K}$. Results showed that after such an outgassing procedure, it is possible to prepare oxygen and carbon free $\mathrm{Zr}, \mathrm{Pd}$ and $\mathrm{ZrPd}_{2}$ surface. In our case, the oxygen and other surface impurities are practically absent on such prepared Zr-based alloy thin films immediately after deposition. As can be seen in Fig. 2, practically no XPS signal from potential contamination atoms like $\mathrm{O}-1 \mathrm{~s}$ and $\mathrm{C}-1 \mathrm{~s}$ is observed.

Figure 3 shows valence bands of nano- and polycrystalline $\mathrm{ZrPd}_{2}$ alloy thin films. The position of the centroids of the valence bands measured for the two samples with significantly different microstructure are practically

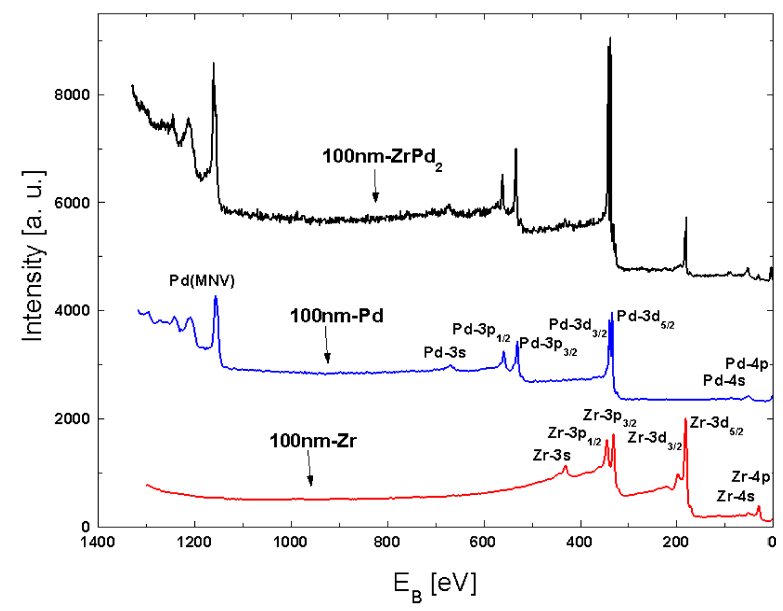

Fig. 2. XPS $\left(\mathrm{Al}-\mathrm{K}_{\alpha}\right)$ spectrum of the freshly prepared polycrystalline $\mathrm{ZrPd}_{2}$ alloy thin film (top curve). For a comparison we also show the XPS spectra measured for in-situ prepared polycrystalline $\mathrm{Pd}$ and $\mathrm{Zr}$ thin films.

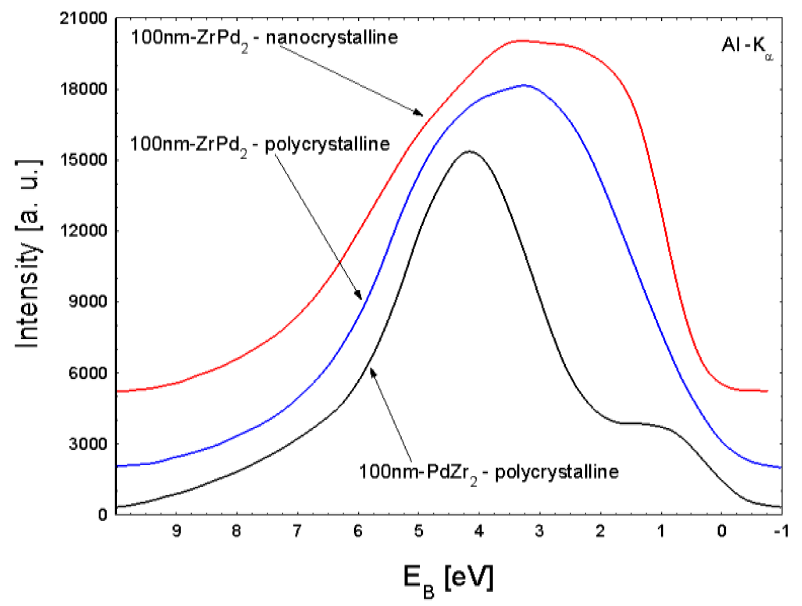

Fig. 3. XPS $\left(\mathrm{Al}-\mathrm{K}_{\alpha}\right)$ valence band spectra for in-situ prepared nanocrystalline and polycrystalline $\mathrm{ZrPd}_{2}$ thin films. For a comparison we show valence band spectrum of polycrystalline $\mathrm{PdZr}_{2}$ thin film.

the same. On the other hand, the XPS valence band for polycrystalline $\mathrm{PdZr}_{2}$ thin film is shifted due to significantly different composition. Furthermore, valence band measured for the nanocrystalline $\mathrm{ZrPd}_{2}$ is considerably broadened compared to that measured for the polycrystalline sample. The above effect could be explained by a strong deformation of the nanocrystals [15-17]. For such nanocrystalline samples the interior of the nanocrystal is constrained and the distances between atoms located at the grain boundaries are expanded.

The XPS valence band measured for polycrystalline thin film was compared with the theoretical XPS valence bands determined from $a b$ initio calculations for single crystal with chemical disorder (Fig. 4). The average grain size measured for the polycrystalline $\mathrm{ZrPd}_{2}$ thin film was 


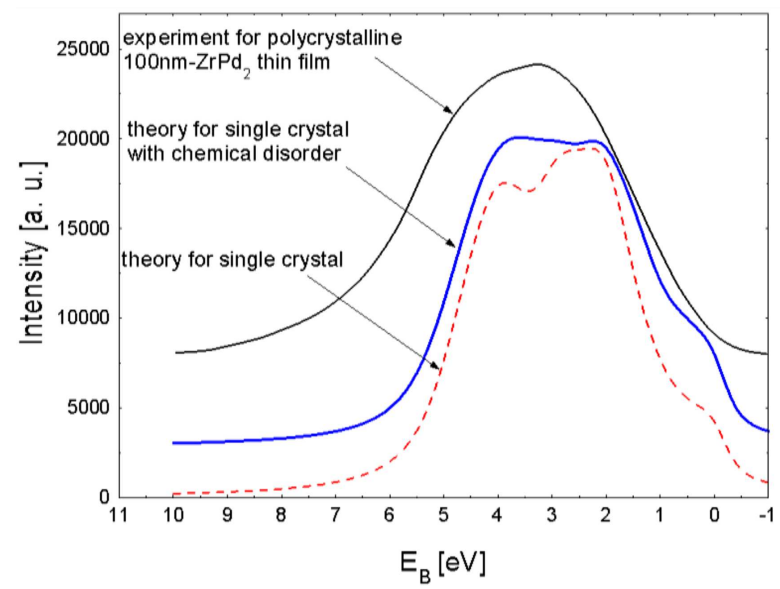

Fig. 4. Theoretical XPS valence bands for ideal single crystal $\mathrm{ZrPd}_{2}$ and single crystal with chemical disorder as shown in Fig. 1. Both calculations are made in $\mathrm{GGA}+U$, with $U(\mathrm{Zr})=2.4 \mathrm{eV}$ and $U(\mathrm{Pd})=3.7 \mathrm{eV}$. For a comparison experimental XPS valence band measured for polycrystalline $\mathrm{ZrPd}_{2}$ thin film.

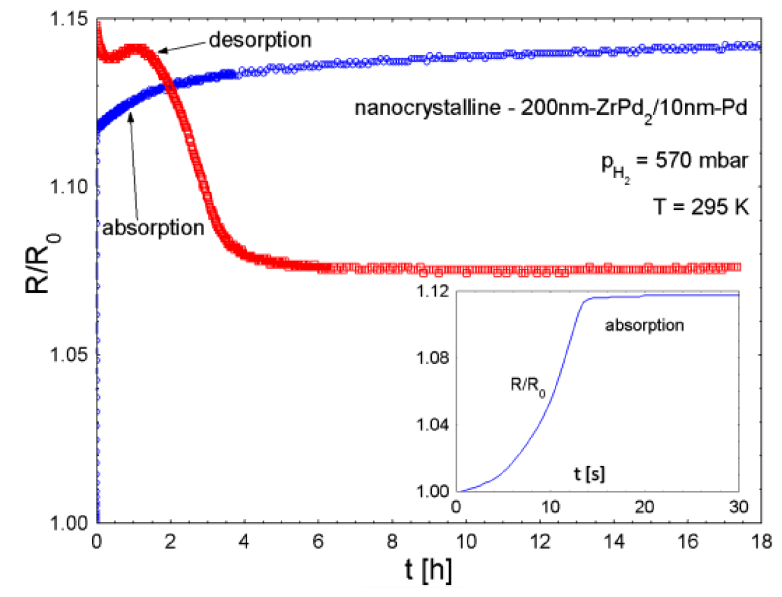

Fig. 5. Absorption and desorption kinetics for nanocrystalline $\mathrm{ZrPd}_{2}$ thin film under a hydrogen pressure of 570 mbar.

estimated as about $100 \mathrm{~nm}$ [23]. The two features near -2.5 and $-3.8 \mathrm{eV}$ observed in the theoretical XPS valence band calculated for ideal single crystal are not detected in the experimental valence band data measured for the polycrystalline sample (see Fig. 4). This is probably as a result of stresses and grain boundaries in real polycrystalline alloy thin film.

In Fig. 5 we show relative resistivity change of the nanocrystalline $100 \mathrm{~nm}-\mathrm{ZrPd}_{2}$ alloy thin film during hydrogen absorption and desorption at a pressure of about 570 mbar. Note that immediately after preparation the alloy thin film was covered in-situ by $10 \mathrm{~nm} \mathrm{Pd}$ layer to catalyze hydrogen absorption and to protect against oxidation. The sample shows rather fast resistivity change during the first $12 \mathrm{~s}$ of RT absorption (see inset in Fig. 5).
On the other hand, the polycrystalline $100 \mathrm{~nm}-\mathrm{ZrPd}_{2}$ covered by $10 \mathrm{~nm}$ of $\mathrm{Pd}$ showed practically no hydrogen absorption (resistivity change). The relatively fast absorption of hydrogen could be interesting in potential application of nanocrystalline $\mathrm{ZrPd}_{2}$ as a membrane for industrial hydrogen purification, in good agreement with recent theory [10].

In conclusions, the different microstructures observed in poly- and nanocrystalline $\mathrm{ZrPd}_{2}$ alloy thin films lead to significant modifications of their valence bands. Therefore, the nanocrystalline $\mathrm{ZrPd}_{2}$ can absorb hydrogen even below 1 bar at RT. Nanocrystalline $\mathrm{ZrPd}_{2}$ thin film materials could find potential application as a membrane for industrial hydrogen purification.

\section{Acknowledgments}

One of the authors (S.P.) would like to thank the Ministry of Science and Higher Education in Poland for financial support within the research project "Diamond grant", 2015-19, No. DI2014010344.

\section{References}

[1] M. Gupta, A.R.P. Gupta, D.J. Singh, Phys. Rev. Lett. 95, 056403 (2005).

[2] M. Ohring, The Materials Science of Thin Films Academic Press, San Diego 1991.

[3] W. D. Nix, Metall. Trans. A 20, 2217 (1989)

[4] L. Smardz, M. Nowak, M. Jurczyk, Int. J. of Hydrogen Energy 37, 3659 (2012).

[5] L. Smardz, M. Jurczyk, K. Smardz, M. Nowak, M. Makowiecka, I. Okońska, Renewable Energy 33, 201 (2008).

[6] A. Pundt, C. Sachs, M. Winter, M. T. Reetz, D. Fritsch, R. Kirchheim, J. All. Comp. 293-295, 480 (1999).

[7] J. W. Phair, R. Donelson, Ind. Eng. Chem. Res. 45, 5657 (2006).

[8] N.W. Ockwing, T.M. Nenoff, Chem. Rev. 107, 4078 (2007).

[9] M. D. Dolan, J. Membr. Sci. 362, 12 (2010).

[10] N. Chandrasekhar, D.S. Sholl, Journal of Membrane Science 453, 516 (2014).

[11] L. Smardz, J. Alloys Comp. 395, 17 (2005).

[12] L. Smardz, K. Smardz, H. Niedoba, J. Magn. Magn. Mater. 220, 175 (2000).

[13] L. Smardz, U. Köbler, W. Zinn, Vacuum 42, 283 (1991).

[14] J. Skoryna, A. Marczyńska, L. Smardz, J. Alloys Comp. 645, S384 (2015).

[15] K. Smardz, L. Smardz, I. Okonska, M. Nowak, M. Jurczyk, Int. J. Hydrog. Energy 33, 387 (2008).

[16] L. Smardz, K. Smardz, M. Jurczyk, J. Jakubowicz, J. All. Comp. 313, 192 (2000).

[17] M. Jurczyk, L. Smardz, M. Makowiecka, E. Jankowska, K. Smardz, J. Phys. Chem. Sol. 65, 545 (2004). 
[18] P. Blaha, K. Schwarz, G. Madsen, D. Kvasnicka, J. Luitz, WIEN2k, An Augmented Plane Wave + Local Orbitals Program for Calculating Crystal Properties, Ed. K. Schwarz, Techn. Universität Wien, Austria, (2001).

[19] A.P. Pikul, D. Kaczorowski, Z. Gajek, J. StępieńDamm, A. Slebarski, M. Werwiński, A. Szajek, Phys. Rev. B 81, 174408 (2010).

[20] J.P. Perdew, K. Burke, M. Ernzerhof, Phys. Rev. Lett. 77, 3865 (1996).
[21] E. Şaşoğlu, C. Friedrich, S. Blügel, Phys. Rev. B $\mathbf{8 3}$ 121101 (2011).

[22] I. Jacob, O. Beeri, E. Elish, J. All. Comp. 221, 129 (1995).

[23] J. Skoryna, S. Pacanowski, A. Marczyńska, M. Werwiński, Ł. Majchrzycki, A. Rogowska, M. Wachowiak, R. Czajka, L. Smardz, Surf. Coat. Techn. 303, 125 (2016). 